\title{
INCLUSIÓN FINANCIERA EN PERÚ Y LATINOAMÉRICA EN TIEMPOS DEL COVID-19
}

\author{
FINANCIAL INCLUSION IN PERU AND LATIN AMERICA IN TIMES OF \\ COVID-19
}

Allan Herminio Vargas García Universidad Nacional Mayor de San Marcos Lima, Perú

ORCID: https://orcid.org/0000-0003-2092-8706

Correo electrónico: avargasg@unmsm.edu.pe

\section{RESUMEN}

El presente estudio analiza las consecuencias del COVID-19 en el Perú y América Latina, en los aspectos de pobreza y desempleo, el impacto en los escenarios económicos-sociales y los indicadores de inclusión financiera existentes en tiempos de pandemia. El objetivo del artículo fue evidenciar la importancia de la inclusión financiera para mitigar los efectos de la crisis del COVID-19 insertando a la población -tradicionalmente excluida - al sistema financiero formal. Como resultado de la investigación, se demuestra que los gobiernos han mitigado los efectos negativos de la pandemia con programas de subsidios y apoyo económico a la población vulnerable a través del sistema financiero; sin embargo, se requiere mejorar las políticas públicas para aprovechar la innovación digital en favor de la población y la necesidad de disminuir las barreras para facilitar la penetración de la inclusión financiera.

Palabras clave: COVID-19; inclusión financiera; pobreza; economía; crisis.

\begin{abstract}
This study analyzes the consequences of COVID-19 in Peru and Latin America regarding the aspects of poverty and unemployment, the impact on the economic-social scenarios, and the existing financial inclusion indicators in times of pandemic. The article's objective was to show the importance of financial inclusion to mitigate the effects of the COVID-19 crisis by inserting the population - traditionally excluded - into the formal financial system. As a result of the research, it is shown that governments have mitigated the negative effects of the pandemic with the implementation of subsidy programs and by offering economic support to the vulnerable population; however, it is necessary to improve public policies to take advantage of digital innovation in benefit of the population, and to lower the barriers that hold back the penetration of financial inclusion.
\end{abstract}

Keywords: COVID-19; financial inclusion; poverty; economy; crisis.

(c) Los autores. Este artículo es publicado por la revista Quipukamayoc de la Facultad de Ciencias Contables, Universidad Nacional Mayor de San Marcos. Este es un artículo de acceso abierto, distribuido bajo los términos de la licencia Creative Commons Atribución 4.0 Internacional (CC BY 4.0) [https://creativecommons.org/licenses/ by/4.0/deed.es] que permite el uso, distribución y reproducción en cualquier medio, siempre que la obra original sea debidamente citada de su fuente original. 


\section{INTRODUCCIÓN}

Los coronavirus son una familia de virus que pueden causar desde infecciones respiratorias leves hasta enfermedades más complejas, como el síndrome respiratorio de oriente medio (MERS) y el síndrome respiratorio agudo severo (SARS). El COVID-19 era una enfermedad desconocida hasta su descubrimiento en Wuhan (República Popular de China) a fines del 2019 (Organización Mundial de la Salud, 2021).

En la actualidad, se ha desencadenado una epidemia de implicancia mundial y hasta febrero de 2021 se ha contabilizado 2,5 millones de muertes ocasionadas por el COVID-19, de las cuales 800 mil muertes corresponden a América Latina y de los 134 millones de contagios, 24 millones pertenecen a dicha región (Statista, 2021).

La experiencia inédita de la pandemia causada por el COVID-19 hace difícil a los gobiernos pronosticar el impacto de la recesión económica y el tiempo de recuperación de la crisis; también restringe la entrega de ayuda social de los diferentes programas gubernamentales. La pandemia evidencia y profundiza las desigualdades socioeconómicas existentes y pone en riesgo el bienestar de generaciones futuras.

Las consecuencias económicas de la pandemia han afectado a la población de bajos recursos, llevándolos al desempleo y pobreza extrema. Mientras el COVID-19 avanza, la población tiene que recurrir a los ahorros, el crédito y la ayuda social para subsistir.

En este contexto, se formula la siguiente pregunta: ¿En qué medida la inclusión financiera ayuda a mitigar los efectos negativos del COVID-19? Para responder a esta pregunta se desarrolla una investigación de alcance descriptivo y tipo documental que analiza la inclusión financiera en el Perú y Latinoamérica en tiempos del COVID- 19.

\section{ALCANCE DE LA REVISIÓN}

\section{Impacto del COVID-19 en la pobreza y desempleo}

La crisis del coronavirus está agravando las desigualdades en los aspectos económicos, de género y sociales en todo el mundo; es un enemigo que ataca a todos sin tregua ni distinción. Alrededor de 207 millones de personas se sumarían a la población de extrema pobreza producto de la pandemia, de esta manera se incrementaría a mil millones las personas que estarían en esa situación en el 2030 (Naciones Unidas, 2020).

En América Latina, la población en extrema pobreza llegaría a 83 millones de personas en el 2020 como consecuencia de la pandemia (Comisión Económica para América Latina y el Caribe, 2020).
Se calcula que alrededor de 1250 millones de obreros se ubican en industrias que presentan grandes disminuciones de producción. Entre las actividades productivas más afectadas se encuentran los sectores de comercio minorista, hoteles, servicios de alimentos y el sector manufacturero (Organización Internacional del Trabajo [OIT], 2020a).

El desempleo en Latinoamérica se estima en 41 millones de personas en el 2020, llegando a un récord histórico e incrementando el hambre y pobreza en la región (OIT, 2020b).

Ante estos hechos, es imperativo que se impulse el acceso a servicios financieros a los sectores menos favorecidos para hacer llegar un servicio eficiente, rápido y de calidad; la inclusión financiera es un medio para ayudar a atenuar los efectos de la crisis mediante las transferencias de efectivo, el crédito, el ahorro y los seguros (BBVA, 2020).

\section{Indicadores económicos durante el COVID-19}

El impacto de las pérdidas económicas globales en el año 2020 se estima entre los USD 77 mil millones hasta los USD 347 mil millones (Ver Figura 1), en esta evaluación preliminar se espera que Asia, en especial China, resulte con el nivel de producción más bajo desde el 2004 afectando así a los continentes de Europa, América y Asia, debido a las medidas de aislamiento para contener el avance del coronavirus (Asian Development Bank, 2020).

Se espera una proyección de crecimiento de la economía mundial en un 4\% en el 2021 (Ver Figura 2), porcentaje que se encuentra por debajo de las proyecciones iniciales del Banco Mundial. La recuperación o caída de la actividad económica global dependerá de factores como la eficiente distribución de vacunas contra el COVID-19, posibles rebrotes del virus, políticas de asistencia social y apoyo económico a la población vulnerable, y riesgos provenientes de la pérdida de continuidad de la cadena de pagos.

América Latina se vio afectada desde un punto de vista económico, social y sanitario; cinco de los diez países en desarrollo con el mayor incremento de mortalidad per cápita se encuentran en este continente. Se calcula que el PBI de la región se redujo un 6.9\% el año 2020 (Ver Figura 3), debido a las medidas para controlar la pandemia que limitaron las actividades económicas. En el año 2021, se proyecta que la actividad económica en América Latina crezca en $3.7 \%$. Sin embargo, considerando un escenario negativo, llegaría a una tasa menor de $1.9 \%$ (Banco Mundial, 2021).

Los riesgos existentes para alcanzar las proyecciones económicas están relacionados con el rebrote de la pandemia, los problemas ocasionados por el endeudamiento y pérdida 


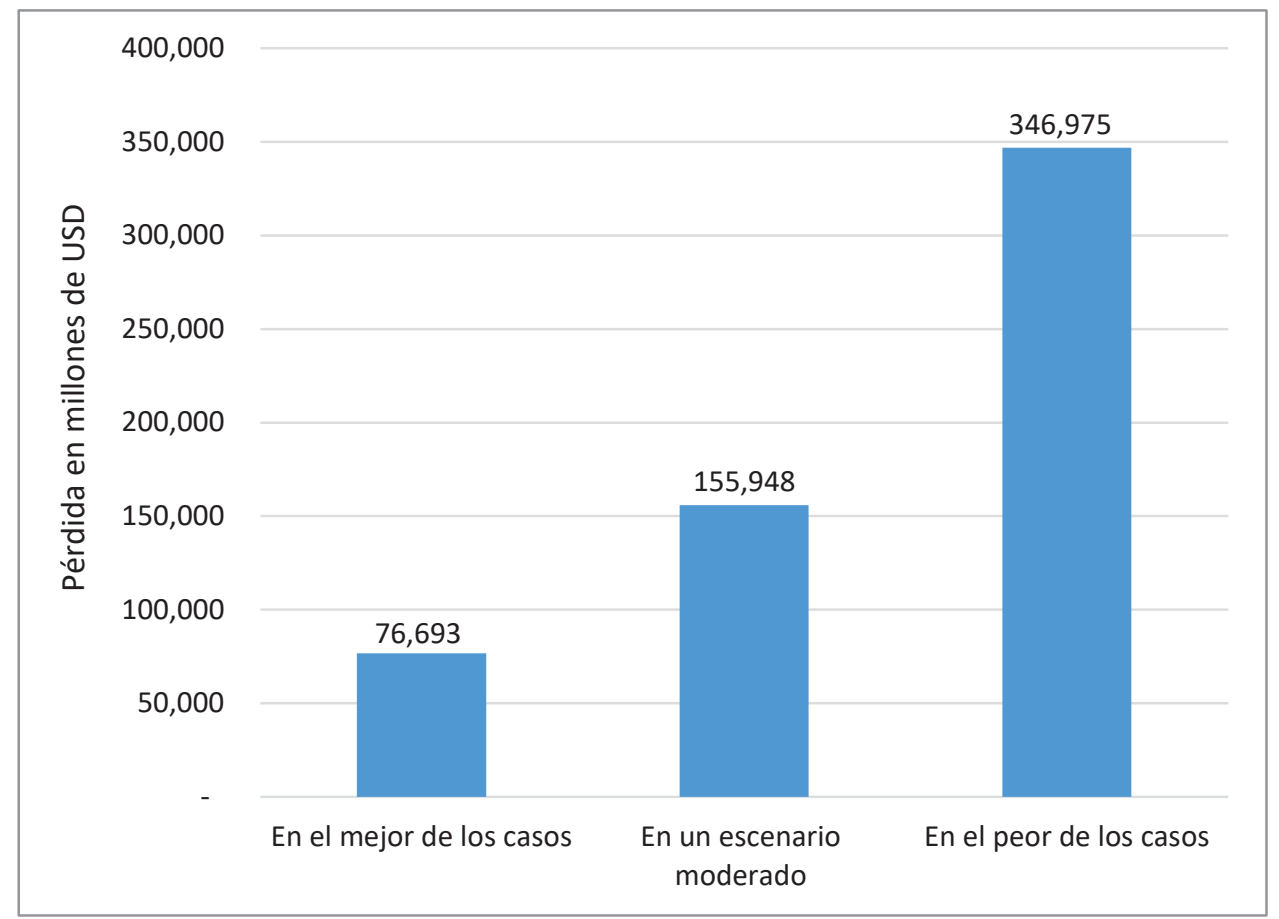

Figura 1. Proyección de pérdidas globales en el PIB debido al COVID-19 en 2020

Fuente: Adaptado del Banco Mundial (2020)

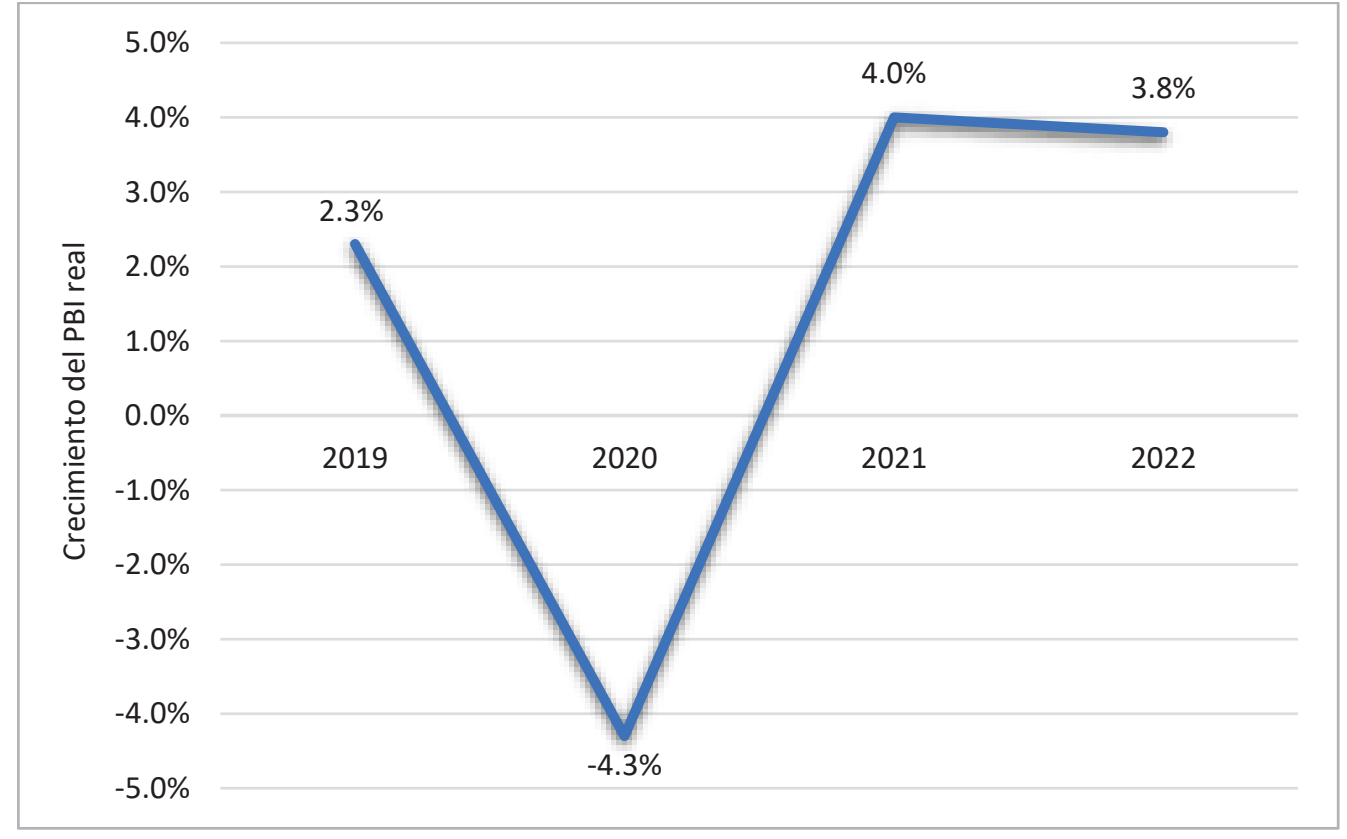

Figura 2. Proyección de crecimiento del PIB mundial durante la pandemia 2021- 2022

Fuente: Adaptado del Banco Mundial (2020) 


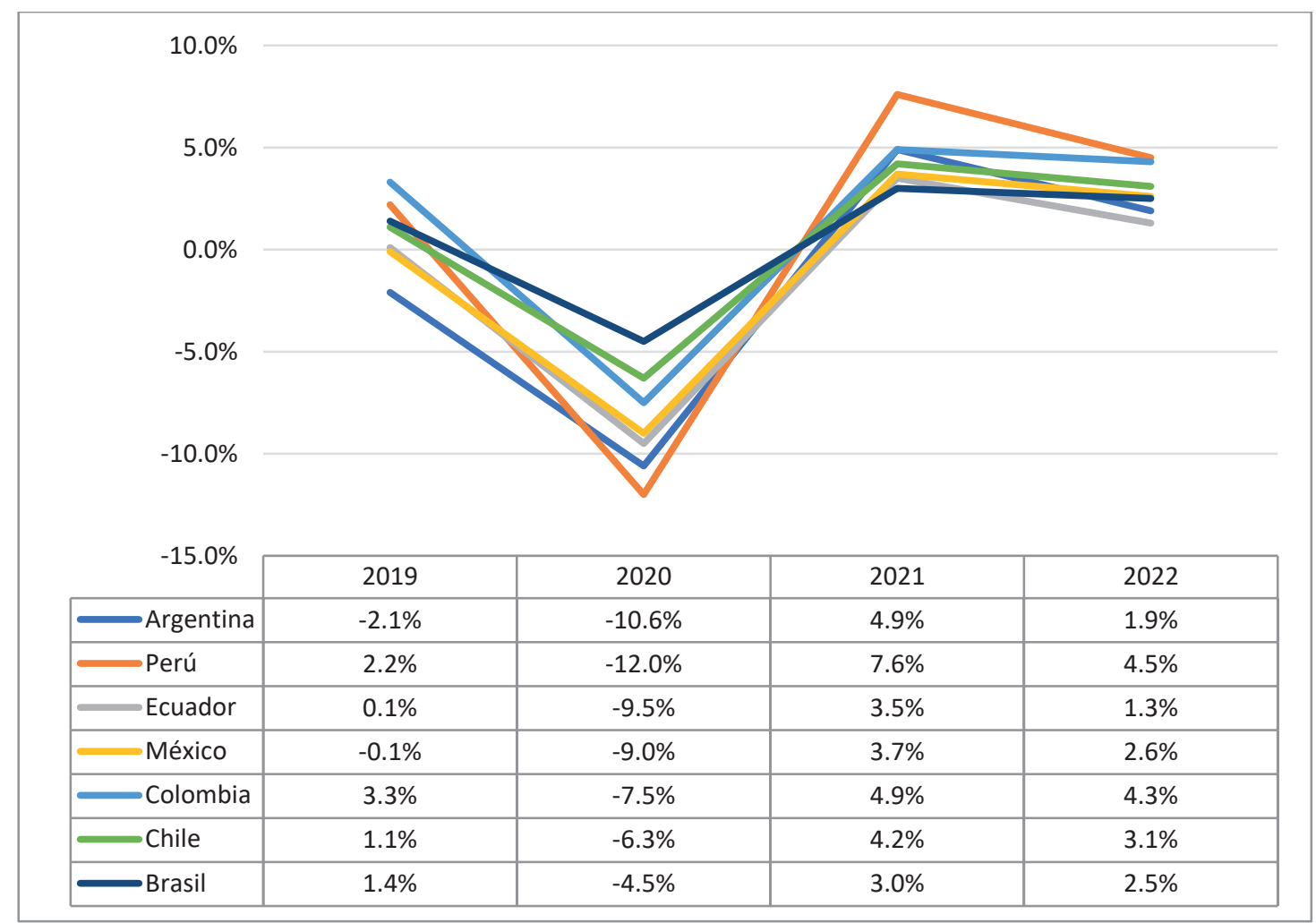

Figura 3. América Latina: Proyección del PIB por país 2021-2022

Fuente: Adaptado del Banco Mundial (2020)

de trabajo de la población, el colapso del flujo turístico y el incremento de la miseria.

América Latina, en su mayoría, adoptó programas de apoyo social. Algunos de los programas más importantes y su alcance en la población son: Bono Familia y Bono Universal de Bolivia (54\% de la población), Ingreso Familiar de Emergencia y Bono de Emergencia de Chile (34\% de la población), Auxilio de Emergencia de Brasil (31\% de la población) y Bono Familiar Universal de Perú (30\% de la población). El público objetivo de los programas de apoyo social COVID-19 fueron los segmentos más pobres y los trabajadores informales que se ganan la vida día a día y que perdieron sus ingresos debido al confinamiento (Banco Mundial, 2020).

Como alternativa para integrar a la población vulnerable, los servicios financieros digitales facilitan a los gobiernos la posibilidad de brindar apoyo económico de los programas de asistencia social de forma rápida y segura a la población de difícil acceso, lo que contribuye a disminuir el golpe negativo de la epidemia del COVID-19. Sin embargo, la crisis es grave y la recesión es de largo plazo.
En el Perú, la economía se ha contraído en un 12\% (2020), provocado por la crisis del COVID-19, y se proyecta una recuperación de 7.6\% (2021) y 4.5\% (2022) dependiendo de la administración efectiva de la vacuna y del manejo político durante la elección presidencial y del Congreso. Los sectores más pobres e informales fueron perjudicados por los aislamientos obligatorios; sin embargo, la inflación se mantuvo estable durante el periodo analizado (Ver Figura 4). Hasta finales de febrero 2021, los contagios llegaron a 1 millón 316 mil y la cantidad de fallecidos llegó a 46 mil personas (Ministerio de Salud, 2021).

\section{La inclusión financiera}

La inclusión financiera significa el uso y acceso de servicios financieros que dispone la población y las empresas; estos recursos proporcionan un mejor entorno para el desarrollo económico y beneficios para el ahorro y consumo; por esta razón, existe un gran interés de los gobiernos por promoverla e intensificarla (Allen, Demirguc-Kunt, Klapper y Martinez, 2016).

Otra definición adecuada es: "La inclusión financiera genera una vía de crecimiento económico focalizada en la 


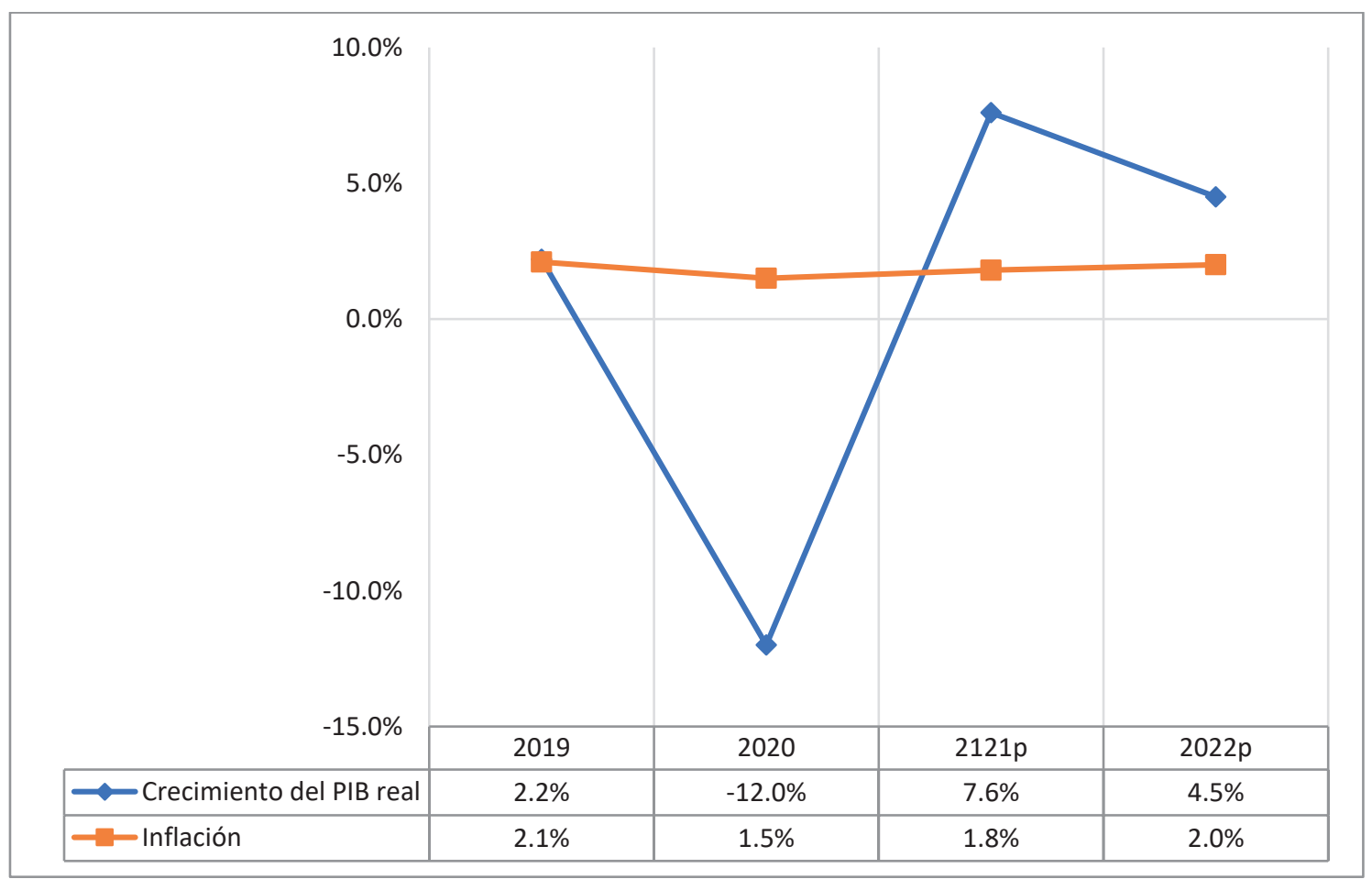

Figura 4. Perú: Proyección del PIB e Inflación 2021-2022

Fuente: Adaptado del Banco Mundial (2020)

población de menores recursos, ya que mediante el acceso y uso de herramientas financieras se mejora la administración de riesgos, ingresos, gastos e inversiones de los hogares" (Orazi, Martinez y Vigier, 2019, p. 200).

\section{Indicadores de inclusión financiera}

La inclusión financiera tiene gran relevancia a nivel regional y mundial, ya que impulsa el desarrollo económico favoreciendo la disminución de la pobreza y la informalidad.

La inclusión financiera se convierte en una herramienta clave para la reducción de la pobreza e impulso a la economía de una región, de ahí que sea una variable de importancia para ser medida y controlada a fin de propiciar su aumento en la población e impactar en su calidad de vida. (Romero, Niebles y Niebles, 2020, p. 14)

Latinoamérica está rezagada en términos de inclusión financiera y debajo de los países desarrollados, lo cual se considera como una alerta importante a considerar durante la crisis del COVID-19. En el año 2019, respecto a cuentas de depósito en bancos comerciales, México cuenta con 98 millones 623 mil, Colombia con 75 millones 728 mil, Argentina con 67 millones 579 mil, Chile con 44 millones 994 mil, Perú con 42 millones 662 mil y finalmente Bolivia con 6 millones 256 mil (Ver Figura 5). En una economía, las cuentas de ahorro actúan como soporte ante choques económicos como el generado por el COVID-19.

En el año 2019, para aclarar por qué las personas no están bancarizadas, la Federación Latinoamericana de Bancos (Felaban) elaboró un informe en el que examina los principales impedimentos que presenta la inclusión financiera. Siendo los más importantes: a) altos costos de los bancos, b) competencia sin supervisión formal, c) trabas legales o regulatorias, d) falta de educación financiera, e) falta de control de las tasas de interés activas y pasivas, f) falta de incentivos del gobierno, g) desconfianza del público en el sistema financiero y h) informalidad económica (Felaban, 2019).

La inclusión financiera alberga la promesa de fomentar el crecimiento y de reducir la pobreza y la desigualdad, en especial movilizando los ahorros y brindando a los sectores de hogares y de empresas mayor acceso a los recursos necesarios para financiar el consumo y la inversión y para tener garantías contra los choques. Además, la 


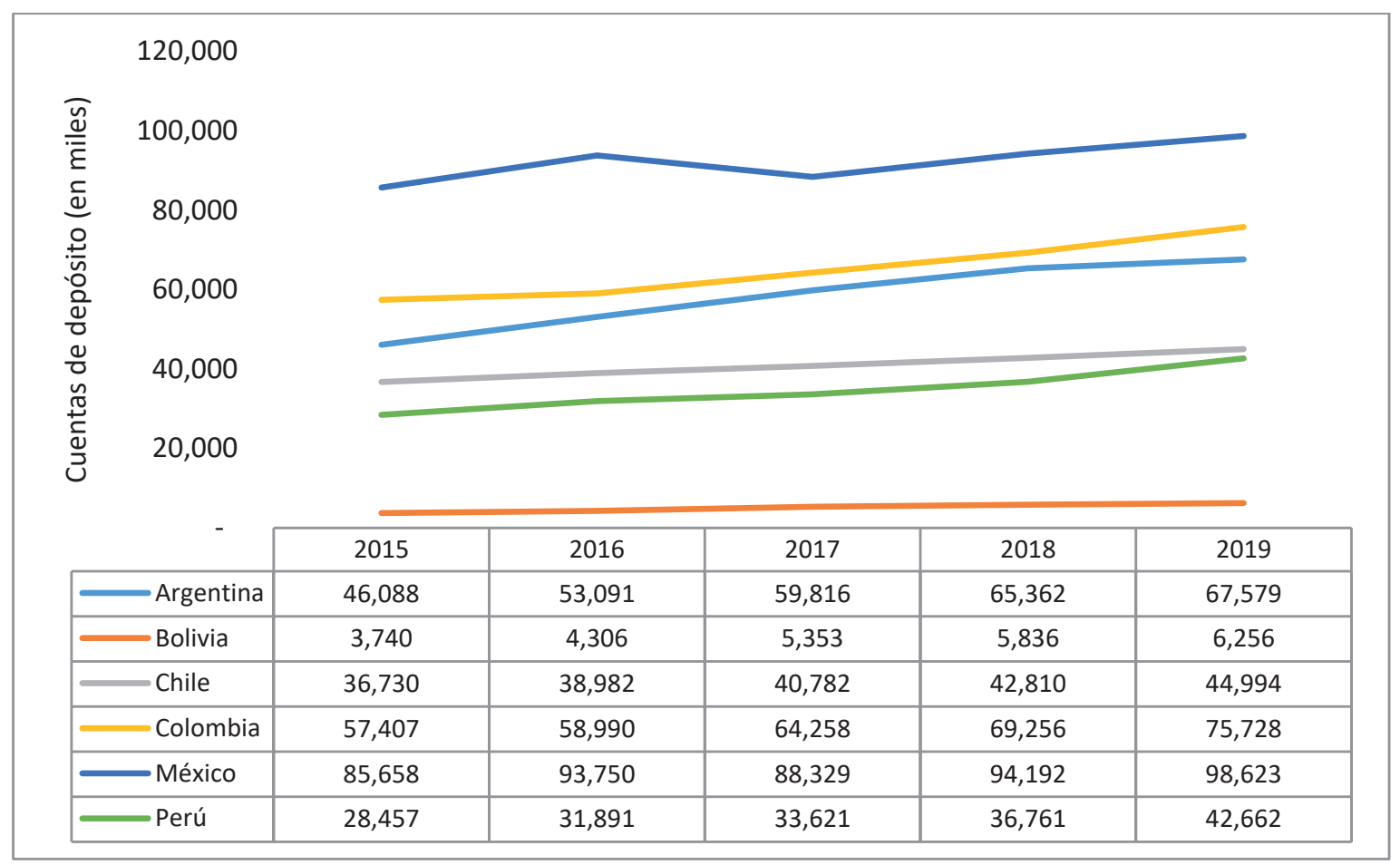

Figura 5. América Latina: cuentas de depósito en bancos comerciales 2015- 2019 (en miles)

Fuente: Adaptado del Fondo Monetario Internacional (2020)

inclusión financiera puede incentivar la formalización. (Dabla-Norris, Deng y Karpowicz, 2015, p. 244)

Conceptos como el ahorro o el acceso al crédito son aspectos importantes de la inclusión financiera. En América Latina, en el año 2019, respecto a cuentas de préstamos en bancos comerciales, Colombia cuenta con 24 millones 463 mil, Argentina con 18 millones 997 mil, Chile con 15 millones 675 mil, Perú con 5 millones 923 mil y finalmente Bolivia con 692 mil (Ver Figura 6).

En Colombia, los actores que tienen contacto directo con la población en general y que son los llamados a desplegar un papel de primera importancia respecto a operar, apoyar y desarrollar las actividades que tienen referencia con la inclusión financiera son los bancos, las compañías de financiamiento y las cooperativas financieras. (Rodríguez, 2017, p. 85)

Debido a la pandemia, resulta lógico preguntar por el futuro de la banca tradicional representada por largas colas, pérdida de tiempo en atención, oficinas lejanas y trámites burocráticos. La digitalización como alternativa de solución a estos problemas permite ahorrar costos, tiempo y ofrece una mayor seguridad en las transacciones. Los canales digitales permiten mayor eficiencia en las operaciones financieras, ofreciendo nuevos modelos de evaluación crediticia, transacciones seguras y productos o servicios de calidad. Este nuevo modelo flexibiliza las barreras de la banca tradicional y permite que la inclusión llegue a la mayoría de la población excluida del sistema financiero.

Los servicios financieros y los trámites se han flexibilizado usando documentos escaneados y firmas digitales. En muchos de los casos, la banca ha cambiado de estrategia para adecuarse al mercado que solicita productos específicos y muy especializados. El objetivo de la banca es implementar un plan de transformación digital e incrementar la inclusión financiera en los próximos años.

En el Perú, el 43\% de adultos tiene una cuenta en una institución financiera, el $8 \%$ ahorró en alguna institución financiera, el $28 \%$ tiene una cuenta de débito, el 15\% tiene créditos vigentes, el 12\% tiene tarjetas de crédito y el 15\% recibe su sueldo con abono en cuenta (Banco Mundial, 2017).

Ante esta coyuntura, el Banco Central de Reserva del Perú y la Superintendencia de Banca y Seguros respondieron a la crisis del COVID-19 disminuyendo la tasa de interés de 


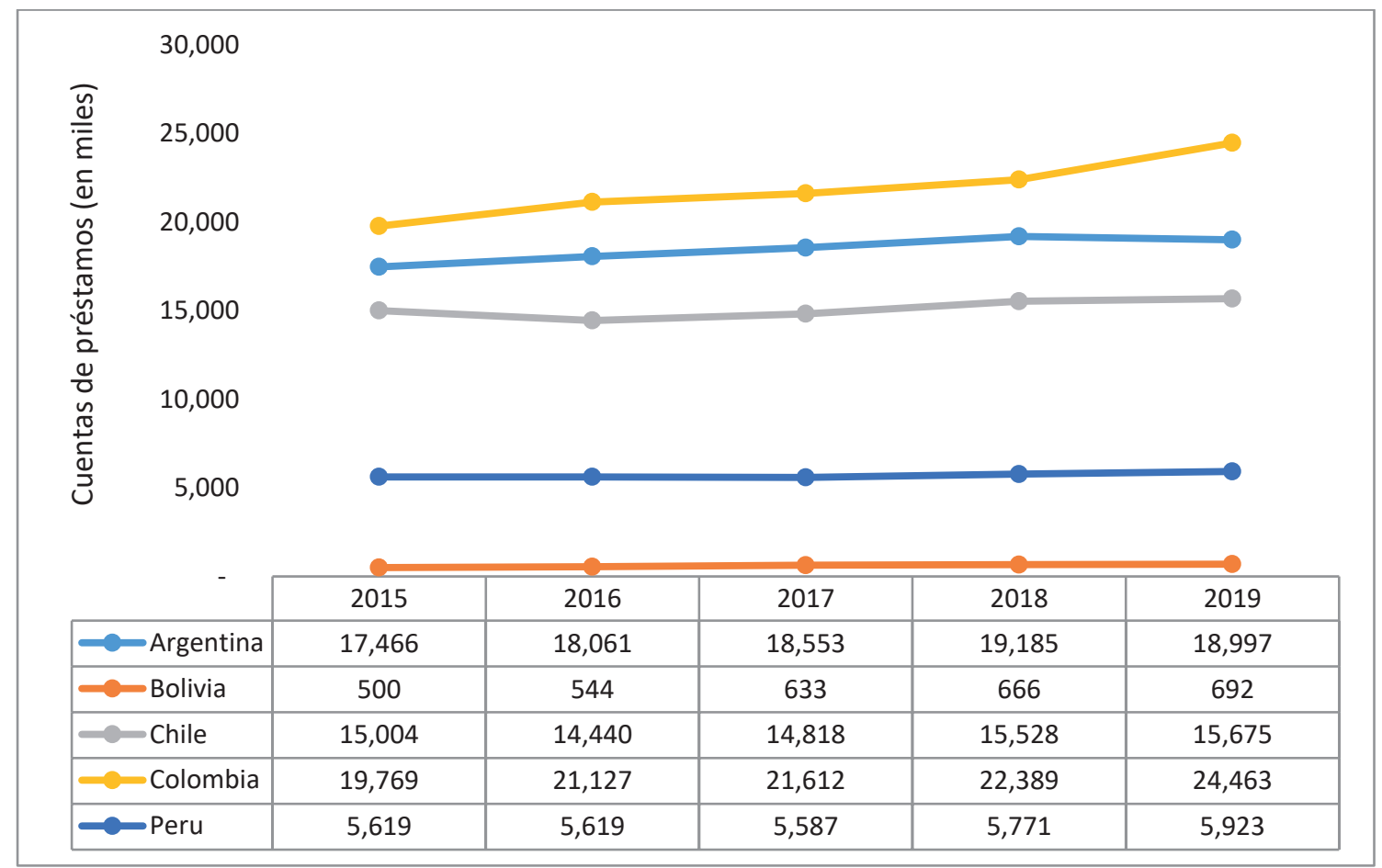

Figura 6. América Latina: cuentas de préstamos en bancos comerciales 2015- 2019 (en miles)

Fuente: Adaptado del Fondo Monetario Internacional (2020)

referencia de $2.25 \%$ a $0.25 \%$, y las tasas de reserva bancaria con la finalidad de dinamizar la economía con una política expansiva; y además reestructuraron los créditos otorgados en el sistema financiero (préstamos). Asimismo, se facilitó el uso de servicios de inclusión financiera como las cuentas básicas y el dinero electrónico.

De esta manera, se promulgó la Ley No 31120 que crea la cuenta-DNI y encarga su administración al Banco de la Nación (BN). Esta es una cuenta vinculada al DNI 100\% digital, por lo que es necesario que el titular tenga un celular con línea y acceso a internet; no se requiere celebrar contratos y el titular manifiesta su aprobación con su usuario y contraseña (Ley No 31120, 2021).

La cuenta-DNI sirve en su primera etapa para: a) realizar pagos de servicios como agua, luz o teléfono, b) transferencias interbancarias, (c) retiro de efectivo sin tarjeta en cajeros y agentes Multired y d) recibir subsidios, prestaciones económicas y aportes de programas sociales del estado.

\section{CONCLUSIONES}

Los países han atenuado el efecto negativo de la crisis del COVID-19 con programas de beneficio, subsidios, prestaciones económicas o aportes sociales a favor de la población vulnerable: $54 \%$ en Bolivia, 34\% en Chile, $31 \%$ en Brasil y 30\% en Perú durante el año 2020 (Banco Mundial, 2020). Utilizando mayormente el sistema financiero tradicional y muy escasamente la banca digital, las entidades del sector financiero deben promover la digitalización de las operaciones y servicios; es decir, realizar pagos y cobros, transferencias interbancarias, aperturas de cuentas, etc. para limitar la dependencia del dinero físico y evitar la exposición a contraer el COVID-19.

Los gobiernos podrán aprovechar la innovación digital si ejecutan políticas públicas coherentes que aprovechen estos beneficios en favor de la población. Según el índice de competitividad digital 2020 que mide la capacidad digital de 63 economías, los países de América Latina mejor posicionados en el ranking son: Chile en el puesto 41, Brasil en el puesto 51, México en el puesto 54, Perú en el puesto 55 y Argentina en el puesto 59 (Institute for Management Development, 2020). Es prioritario que la digitalización llegue a los países en desarrollo donde la tecnología es incipiente, la infraestructura escasa y donde existe una cantidad mínima de personas capacitadas para conducir los procesos de transformación. Asimismo, la transformación digital implica un proceso de 
cambio tecnológico y cultural de las instituciones financieras, y esto significa invertir tiempo y dinero.

Para impulsar la penetración de la inclusión financiera en América Latina es necesario que las instituciones público y privadas trabajen para disminuir las barreras que impiden su desarrollo respecto a sus dimensiones: a) el acceso, que se refiere a la disponibilidad de los servicios financieros u oferta de servicios, y b) el uso, que se refiere a la frecuencia de utilización; es decir, la demanda de servicios financieros.

En artículo desarrolla un tema de carácter inédito respecto a las variables inclusión financiera y el COVID-19, por lo tanto, se recomienda profundizar en el estudio de estas variables por existir una gran cantidad de población que todavía no se encuentra incluida financieramente. Hasta el momento, según los resultados obtenidos, los avances de la inclusión financiera se están desarrollado muy lentamente.

\section{REFERENCIAS}

Allen, F., Demirguc-Kunt, A., Klapper, L., \& Martinez, M. (Julio de 2016). The foundations of financial inclusion: Understanding ownership and use of formal accounts. Journal of Financial Intermediation, 27, 1-30. https:// doi.org/10.1016/j.jfi.2015.12.003

Asian Development Bank. (2020). The Economic Impact of the COVID-19. Recuperado de: https://www. adb.org/sites/default/files/publication/571536/ adb-brief-128-economic-impact-covid19-developing-asia.pdf

Banco Mundial. (2017). Global Findex Database. Recuperado de: https://globalfindex.worldbank.org/

Banco Mundial. (2020). El costo de mantenerse sano. Recuperado de: https://www.bancomundial.org/es/region/lac/publication/el-costo-de-mantenerse-sano

Banco Mundial. (2021). Perspectivas Económicas Mundiales. Recuperado de: https://www.bancomundial.org/ es/publication/global-economic-prospects

BBVA. (29 de junio de 2020). Educación Financiera. Recuperado de: https://www.bbva.com/es/inclusion-financiera-para-apoyar-a-las-personas-afectadas-por-la-crisis-del-coronavirus/

Comisión Económica para América Latina y el Caribe. (6 de Junio de 2020). FAO Y CEPAL: Millones de personas pueden caer en la pobreza extrema y el hambre en 2020 en América Latina y el Caribe debido al impacto de la pandemia. Recuperado de: https://www.cepal.org/ es/comunicados/fao-cepal-millones-personas-pueden-caer-la-pobreza-extrema-hambre-2020-america-latina

Dabla-Norris, E., Deng, Y., \& Karpowicz, I. (2015). Inclusión Financiera: Un enfoque centrado en Amércia Latina. Centro de Estudios Monetarios Latinoamericanos, 61, 244-281. Recuperado de: https://www.cemla.org/ PDF/boletin/PUB_BOL_LXI-04.pdf

Federación Latinoamericana de Bancos. (2019). V Informe de Inclusión Financiera. Recuperado de: https:// felaban.s3-us-west-2.amazonaws.com/publicaciones/ archivo20191120203800PM.pdf

Institute for Management Development. (2020). World digital competitiveness ranking. Recuperado de: https:// www.imd.org/wcc/world-competitiveness-center-rankings/world-digital-competitiveness-rankings-2020/

Ley $N^{\circ} 31120$, Ley que regula la cuenta documento nacional de identidad, (Cuenta-DNI). (2021). Congreso de la República. Diario Oficial El Peruano, 7 de febrero.

Ministerio de Salud. (Febrero de 2021). Sala Situacional Covid-19 Perú. Recuperado de: https://covid19.minsa. gob.pe/sala_situacional.asp

Naciones Unidas. (2020). Noticias ONU. Recuperado de: https://news.un.org/es/story/2020/12/1485042

Orazi, S., Martinez, B., \& Vigier, H. (2019). La inclusión financiera en América Latina y Europa. Ensayos de Economía, 29, 181-204. https://doi.org/10.15446/ede. v29n55.79425

Organización Internacional del Trabajo. (2020a). Observatorio OIT: El COVID-19 y el mundo del trabajo. Recuperado de: https://www.ilo.org/wcmsp5/groups/ public/---dgreports/---dcomm/documents/briefingnote/wcms_740981.pdf

Organización Internacional del Trabajo. (1 de julio de 2020b). OIT: Fuerte aumento de desempleo en América Latina y el Caribe deja a millones sin ingresos. Recuperado de: https://www.ilo.org/americas/sala-de-prensa/ WCMS_749663/lang--es/index.htm

Organización Mundial de la Salud. (2021). Orientación para el público. Recuperado de: https://www.who.int/ es/emergencies/diseases/novel-coronavirus-2019/advice-for-public/q-a-coronaviruses

Rodríguez, G. (2017). Eficiencia de la inclusión financiera en Colombia, 2014. Semestre Económico, 20, 67-93. https://doi.org/10.22395/seec.v20n44a4 
Romero, Y., Niebles, W., \& Niebles, L. (2020). La inclusión financiera analizada desde una técnica de reducción de dimensiones. Desarrollo Gerencial, 12, 1-17. https:// doi.org/10.17081/dege.12.1.3588
Statista. (2021). Coronavirus (COVID-19) - Datos estadísticos. Recuperado de: https://es.statista.com/temas/5901/el-coronavirus-de-wuhan/ 
